\title{
Current Status of Local Drug Delivery Systems in the Treatment of Periodontal Diseases
}

\author{
Dk Siti Najwa Rashidah Pg Hj Ismail ${ }^{1}$, Rajan Rajabalaya ${ }^{1}$, Sheba R David ${ }^{1}$ and Jagjit Singh Dhaliwal ${ }^{1 *}$ \\ ${ }^{*}$ PAPRSB Institute of Health Sciences, Universiti Brunei Darussalam, Jalan Tungku Link BE1410, Brunei Darussalam
}

${ }^{\star}$ Correspondence Author: Dr. Jagjit Singh Dhaliwal, PAPRSB Institute of Health Sciences, Universiti Brunei Darussalam, Jalan Tungku Link BE1410, Brunei Darussalam; Email: jagjit.dhaliwal@ubd.edu.bn

Received: August 25, 2019; Accepted: September 06, 2019; Published: September 11, 2019;

\begin{abstract}
Periodontal disease includes many pathological conditions affecting the periodontium, but gingivitis and periodontitis are the more common types. Gingivitis is a progressive condition, although it is reversible, when left untreated it can lead to periodontitis. Microbial species have a major role in the aetiology of periodontitis.

Method: Information was derived from research papers using PubMed, Science Direct, and Google Scholar using the keywords local drug delivery system, treatment, and periodontal disease. The search included articles up to 2018 with majorly in vivo studies in patients with periodontitis. The usage of local drug delivery systems with controlled or sustained release mechanisms may provide slightly better therapeutic effect in comparison with patients who undergo scaling and root planning only.
\end{abstract}

Conclusion: The present review of the literature of the currently available local drug delivery systems in the treatment of periodontal diseases.

Keywords: Gingivitis, Periodontal Diseases, Periodontium, Scaling

\section{Introduction}

Periodontal disease is a term which comprises several pathological conditions involving the periodontium, which includes the gum, alveolar bone, dental cementum, and periodontal ligament [1]. The more common conditions of periodontal diseases are gingivitis and periodontitis. Periodontal disease is the most prevalent oral condition of the worldwide population, with gingivitis affecting $50 \%$ to $90 \%$ of adults $[2,3]$. Gingivitis is the mildest type of periodontal disease. It is a localised inflammation of the gum tissue (gingiva) caused by bacteria in the dental plaque, which is a microbial biofilm that forms on the teeth and the gingiva. Cultural studies have shown that there are more than 700 distinct microbial species that can be found in the dental plaque, although only a small group has been confirmed to contribute to the cause and progression of periodontal disease $[3,4]$

Gingivitis, when left untreated, can progress to periodontitis $[3,5]$. Unlike gingivitis, which is confined to the gingiva, periodontitis leads to the loss of connective tissues supporting or surrounding the teeth. This loss of gingiva, alveolar bone, and periodontal ligament creates deep "pockets". When these deep periodontal pockets have formed and is filled with microbes, the condition becomes highly irreversible, and eventually may lead to loss of teeth [5].

\section{Literature Research}

\section{Search strategy}

A literature search with several restrictions was done electronically through the following databases: PubMed, Google Scholar, and Science Direct, using search terms that have been summarised in (Table 1).
Table 1. Number of results yielded by searching using keywords through three different databases.

\begin{tabular}{|c|c|c|}
\hline Database & Search term(s) & $\begin{array}{l}\text { Number of } \\
\text { results }\end{array}$ \\
\hline \multirow[t]{3}{*}{ PubMed } & $\begin{array}{l}\text { (local drug delivery system) AND periodontal } \\
\text { disease }\end{array}$ & 149 \\
\hline & $\begin{array}{l}\text { (local drug delivery system) AND "periodontal } \\
\text { disease" }\end{array}$ & 38 \\
\hline & $\begin{array}{l}\text { (local drug delivery system [Title/Abstract]) } \\
\text { AND periodontal disease [Title/Abstract] }\end{array}$ & 6 \\
\hline \multirow[t]{3}{*}{ Science Direct } & $\begin{array}{l}\text { local drug delivery system in treatment of } \\
\text { periodontal disease }\end{array}$ & 2,458 \\
\hline & $\begin{array}{l}\text { "local drug delivery system" AND "periodontal } \\
\text { disease" }\end{array}$ & 46 \\
\hline & $\begin{array}{l}\text { "local drug delivery system" AND "treatment of } \\
\text { periodontal disease" }\end{array}$ & 20 \\
\hline \multirow[t]{3}{*}{ Google Scholar } & $\begin{array}{l}\text { local drug delivery system in treatment of } \\
\text { periodontal disease }\end{array}$ & 58,600 \\
\hline & $\begin{array}{l}\text { "local drug delivery system" AND "periodontal } \\
\text { disease" }\end{array}$ & 807 \\
\hline & $\begin{array}{l}\text { "local drug delivery system" AND "treatment of } \\
\text { periodontal disease" }\end{array}$ & 321 \\
\hline
\end{tabular}

\section{Inclusion and exclusion criteria}

The search was restricted to research articles written in English, and the search included studies from 1979 up to 2018, since 1979 was 
the year that local drug delivery systems were first considered. Apart from articles that do not meet the criteria mentioned, animal studies were also not included.

\section{History of Treatment}

As mentioned previously, it has been proven that the bacteria-filled film is one of the main causes of periodontal diseases. The traditional methods of non-surgical treatment of periodontal disease, including mechanical scaling and root planing, did not guarantee improvements of the disease. Treatment of periodontitis focuses mainly on reducing the total microbial count, hence scaling and root planing needs to have an adjunct therapy, in other words, the antimicrobial agents. It was Dr. Max Goodson who pioneered and developed the concept of local drug delivery systems in 1979 [6]. This discovery has led to the increase of studies regarding local drug delivery systems pertaining to periodontal disease in the last decade.

\section{Advantages of local antimicrobial drug delivery directly into periodontal pocket}

The advantages of delivering antimicrobial agents directly to the target instead of taking systemic agents $[7,8]$. These are included and not limited to direct access to the targeted diseases, first-pass metabolism is bypassed, avoids problems regarding the gastrointestinal system, which is a common occurrence with drugs that are orally administered, able to provide more rapid absorption because of the rich blood supply' reduction in cost of treatment, less chances of antimicrobial resistance and suitable for patients who cannot swallow. However, there are still some limitations, which include inability to administer local irritants, limited dose because of the small area and cost to manufacture delivery devices may get expensive.

\section{Local drug delivery systems}

Drugs that need to be delivered locally are done so by inserting them into a vehicle in the form of fibres, gels, strips, among others, which will be discussed in Table 2 below. The ideal characteristics for that are desired for a local anti-microbial agent are able to deliver the drug to the target, in other words, the base of the pocket, has a therapeutic concentration in the pocket, able to maintain the concentration of drug for a period of time where the drug gives therapeutic effect and exhibits little side effects.

\section{Fibres}

Fibres are thread-like devices with a reservoir-based sustained release system. They are circumferentially placed inside the periodontal pockets using an applicator, and to ensure the controlled release of drug, the fibres are secured by applying cyanoacrylate as an adhesive [9].

\section{Actisite}

Actisite was introduced in 1994 and was the first controlled-release antimicrobial product to be commercialised. It is $23 \mathrm{~cm}$ long and 0.55 $\mathrm{mm}$ wide, delivering $12.7 \mathrm{mg}$ of tetracycline hydrochloride. The fibre is non-biodegradable and has to be removed after 10 days, which is the end of the therapy. In comparison with $250 \mathrm{mg}$ of tetracycline delivered orally which results in $1 \mu \mathrm{g} / \mathrm{ml}$ in the gingival crevicular fluid, the locally delivered Actisite achieves an initial concentration of $1590 \mu \mathrm{g} / \mathrm{ml}$ in the periodontal pocket. The concentration level remained at a mean of $1300 \mu \mathrm{g} / \mathrm{ml}$ for 7 days [7]

\section{Films}

Film is a form of matrix delivery system where the drug is distributed throughout the polymer, and it is released by either drug diffusion, or erosion or dissolution of matrix. This system is more commonly used as it has several advantageous characteristics. The size and shape of the films is flexible it can be easily changed to fit the dimensions of pocket needed to be treated. Larger-sized films can be applied onto the cheek mucosa, or they can also be divided into smaller sizes to be placed into the pocket [9].

\section{Injectable systems}

Injectable systems have an added advantage of easy and rapid application. Antimicrobial agents can be delivered using a syringe directly into the periodontal pocket, without the patient experiencing pain. The cost and time taken for the therapy is also considerably lower when compared to delivery systems that need to be applied securely. Furthermore, the injectable system should be able to fill the pocket, hence reaching more pathogens [48].

\section{Gels}

Gels are semisolid mucoadhesive systems that have also received attention for the targeted delivery of antimicrobial agents, offering some advantages [8]creation of periodontal pocket and resorption of alveolar bone, resulting in the disruption of the support structure of teeth. According to WHO, 10-15\% of the global population suffers from severe periodontitis. The disease results from the growth of a diverse microflora (especially anaerobes. For instance, in terms of preparation and administration, they are easier to prepare. A downside is that gels have faster drug releasing rates. Gels are applied sublingually using a blunt cannula and a syringe [48].

\section{Strips and compacts}

Strips are thin and elongated matrix bands where the drug will be distributed throughout the system. Acrylic strips filled with different antimicrobial agents have been developed, and those containing tetracycline or metronidazole were found to have best improved the parameters of periodontitis [49].

\section{Vesicular liposomal systems}

Vesicular liposomal systems are investigated intently in order to be used in periodontal diseases. This is because they are designed to mimic the bio-membranes in terms of structure and their behaviour [9].

\section{Microparticle systems}

Microspheres are solid structures that are spherical in shape, with sizes ranging from 1 to $1000 \mu \mathrm{m}$. The drug is dispersed throughout the matrix. To prepare microspheres, non-biodegradable and biodegradable materials are both being investigated. These materials 
Jagjit Singh Dhaliwal (2019) Current Status of Local Drug Delivery Systems in the Treatment of Periodontal Diseases.

Table 2. Summary of some local drug delivery systems [9].

\begin{tabular}{|c|c|c|c|}
\hline Local drug delivery system & Polymer matrix & Incorporated drug & Reference \\
\hline \multirow[t]{4}{*}{ Fibres } & Cellulose acetate & 1. Tetracycline $\mathrm{HCl}$ & {$[6]$} \\
\hline & & 2. Chlorhexidine & {$[10]$} \\
\hline & Ethylene vinyl acetate & Tetracycline $\mathrm{HCl}$ & {$[11]$} \\
\hline & Poly-(E-caprolactone) (PCL) & Tetracycline $\mathrm{HCl}$ & [11] \\
\hline \multirow[t]{14}{*}{ Films } & Ethyl cellulose & 1. Metronidazole & {$[12]$} \\
\hline & & 2. Tetracycline $\mathrm{HCl}$ & {$[13]$} \\
\hline & & 3. Minocycline & {$[14]$} \\
\hline & Cross-linked atelocollagen & Tetracycline & {$[15]$} \\
\hline & Gelatin $\left(\right.$ Byco $^{\circledR}$ protein) & Chlorhexidine diacetate & {$[16]$} \\
\hline & Collagen & Chlorhexidine gluconate & {$[17]$} \\
\hline & Chitosan & Taurine & {$[18]$} \\
\hline & $\begin{array}{l}\text { Chitosan + Polylactide-co-glycolic acid } \\
\text { (PLGA) }\end{array}$ & Iproflavone & [19] \\
\hline & Chitosan + PCL & Metronidazole & {$[20]$} \\
\hline & Polyvinyl alcohol + carboxymethyl chitosan & Ornidazole & {$[21]$} \\
\hline & PLGA & 1. Tetracycline & {$[22]$} \\
\hline & & 2. Amoxycillin + metronidazole & {$[23]$} \\
\hline & Eudragit $L^{\circledR}$ and Eudragit $S^{\circledR}$ & Clindamycin & {$[24]$} \\
\hline & PCL & Minocycline & {$[25]$} \\
\hline \multirow[t]{7}{*}{ Gels } & Chitosan & Metronidazole & {$[26]$} \\
\hline & Hydroxyethyl cellulose + polyvinylpyrrolidone & Tetracycline & {$[27]$} \\
\hline & Poloxamer 407 + Carbopol 934P & Propolis & {$[28]$} \\
\hline & $\operatorname{Poly}(\alpha$-lactide $)+N$-methyl 2-pyrrolidone & 1. Sanguinarium & [29] \\
\hline & & 2. Doxycycline hyclate & {$[30]$} \\
\hline & Glycerol monooleate + sesame oil & Metronidazole & {$[31]$} \\
\hline & PLGA & Tetracycline & {$[32]$} \\
\hline \multirow[t]{9}{*}{ Strips } & Polyethylmetha acrylate (acrylic) & 1. Tetracycline $\mathrm{HCl}$ & {$[33]$} \\
\hline & & 2. Metronidazole & {$[34]$} \\
\hline & Hydroxypropyl cellulose & 1. Chlorhexidine, tetracycline & {$[35]$} \\
\hline & & 2. Doxycycline & {$[36]$} \\
\hline & Hydroxypropyl cellulose + methacrylic acid & Ofloxacin & {$[37,38]$} \\
\hline & Polyhydroxybutyric acid & Tetracycline $\mathrm{HCl}$ & {$[39]$} \\
\hline & PLGA & Tetracycline $\mathrm{HCl}$ & {$[40]$} \\
\hline & Xanthan & Chlorhexidine & {$[41]$} \\
\hline & Ethyl cellulose & Chlorhexidine & {$[42]$} \\
\hline \multirow[t]{2}{*}{ Vesicular liposomal systems } & Phosphatidylinositol & Triclosan & {$[43]$} \\
\hline & Immunoliposomes & Anti-oralis & [44] \\
\hline Microparticle systems & PLGA & Tetracycline & {$[45]$} \\
\hline \multirow[t]{3}{*}{ Nanoparticle systems } & PLGA & Triclosan & {$[46]$} \\
\hline & Cellulose acetate phthalate & Triclosan & {$[46]$} \\
\hline & Chitosan & Antisense oligonucleotide & {$[47]$} \\
\hline
\end{tabular}


include natural polymers, modified natural substances, and synthetics. They can be formulated into chips, dental paste, or even directly injected into the targeted area $[8,49]$ creation of periodontal pocket and resorption of alveolar bone, resulting in the disruption of the support structure of teeth. According to WHO, 10-15\% of the global population suffers from severe periodontitis. The disease results from the growth of a diverse microflora (especially anaerobes.

\section{Nanoparticle systems}

Nanoparticles have sizes ranging from 10 to $1000 \mathrm{~nm}$, which enables them to penetrate through regions that may not be reached by other delivery systems. This is a major advantage above the other systems like microparticles, since the ability to reach these otherwise neglected areas result in a decreased frequency of administration and it also provides a more uniform distribution of the drug [9]. For most of the local drug delivery systems, there is only a limited number of studies that have been published. Even though there are studies available, it is difficult to compare between different trials as the therapy given to the participating patients vary greatly.

\section{Conclusion}

Local delivery drug systems are seemingly a good alternative to deliver antimicrobial agents compared to systemic delivery. They produce fewer side effects, which could improve patient compliance. Since there are no studies proving the effective use of locally delivered drugs as a monotherapy, local drug delivery system remains to be a good adjunct therapy.

\section{Acknowledgement}

This literature review promoted by the Universiti Brunei Darussalam through the Pharmacy and dentistry team for their bachelor student's studentship.

\section{References}

1. Kaplish V, Walia MK, Kumar SLH (2013) Local drug delivery systems in the treatment of periodontitis: A review. Pharmacophore 4: 39-49.

2. Nazir MA (2017) Prevalence of periodontal disease, its association with systemic diseases and prevention. International journal of health sciences 11: 72-80.

3. Pihlstrom BL, Michalowicz BS, Johnson NW (2005) Periodontal diseases. Lancet 366: 1809-1820.

4. Herrera D, Matesanz P, Bascones-Martínez A, Sanz M (2012) Local and systemic antimicrobial therapy in periodontics. Journal of Evidence-Based Dental Practice 12: 50-60.

5. Kinane DF, Stathopoulou PG, Papapanou PN (2017) Periodontal diseases. Nature Reviews Disease Primers 3: 1-14.

6. Goodson JM, Haffajee A, Socransky SS (1979) Periodontal therapy by local delivery of tetracycline. Journal of Clinical Periodontology 6: 83-92.

7. Nair SC, Anoop KR (2012) Intraperiodontal pocket: An ideal route for local antimicrobial drug delivery. Journal of advanced pharmaceutical technology \& research 3: 9-15.

8. Joshi D, Garg T, Goyal AK, Rath G (2016) Advanced drug delivery approaches against periodontitis. Drug Delivery 23: 363-377.

9. Jain N, Jain GK, Javed S, Iqbal Z, Talegaonkar S, Ahmad FJ, Khar RK (2008) Recent approaches for the treatment of periodontitis. Drug discovery today 13: 932-943.

10. Coventry J, Newman HN (1982) Experimental use of a slow release device employing chlorhexidine gluconate in areas of acute periodontal inflammation. Journal of Clinical Periodontology 9: 129-133.

11. Tonetti M, Cugini MA, Goodson JM (1990) Zero-order delivery with periodontal placement of tetracycline-loaded ethylene vinyl acetate fibers. Journal of Periodontal Research 25: 243-249.
12. Golomb G, Friedman M, Soskolne A, Stabholz A, Sela MN (1984) Sustained Release Device Containing Metronidazole for Periodontal Use. Journal of Dental Research 63: 1149-1153.

13. Azoury R, Elkayam R, Friedman M (1988) Nuclear Magnetic Resonance Study of an Ethyl Cellulose Sustained-Release Delivery System II: Release Rate Behavior of Tetracycline. Journal of Pharmaceutical Sciences 77: 428-431.

14. Elkayam R, Friedman M, Stabholz A, Soskolne AW, Sela MN, Golub L (1988) Sustained release device containing minocycline for local treatment of periodontal disease. Journal of Controlled Release 7: 231-236.

15. Minabe M, Uematsu A, Nishijima K, Tomomatsu E, Tamura T, Hori T, Hino T (1989) Application of a Local Drug Delivery System to Periodontal Therapy: Journal of Periodontology 60: 113-117.

16. Steinberg D, Friedman M, Soskolne A, Sela MN (1990) A New Degradable Controlled Release Device for Treatment of Periodontal Disease: In Vitro Release Study. Journal of Periodontology 61: 393-398.

17. Kondreddy K, Ambalavanan N, Ramakrishna T, Kumar RS (2012) Effectiveness of a controlled release chlorhexidine chip (PerioColTM-CG) as an adjunctive to scaling and root planing when compared to scaling and root planing alone in the treatment of chronic periodontitis: A comparative study. Journal of Indian Society of Periodontology 16: 553-557.

18. Ozmeriç N, Ozcan G, Haytaç CM, Alaaddinoğlu EE, Sargon MF, Senel S (2000) Chitosan film enriched with an antioxidant agent, taurine, in fenestration defects. Journal of biomedical materials research 51: 500-503.

19. Perugini P, Genta I, Conti B, Modena T, Pavanetto F (2003) Periodontal delivery of ipriflavone: new chitosan/PLGA film delivery system for a lipophilic drug. International journal of pharmaceutics 252: 1-9.

20. El-Kamel AH, Ashri LY, Alsarra IA (2007) Micromatricial metronidazole benzoate film as a local mucoadhesive delivery system for treatment of periodontal diseases. AAPS PharmSciTech 8: 184-194.

21. Wang LC, Chen XG, Zhong DY, Xu QC (2007) Study on poly(vinyl alcohol)/ carboxymethyl-chitosan blend film as local drug delivery system. Journal of Materials Science: Materials in Medicine 18: 1125-1133.

22. Agarwal RK, Robinson DH, Maze GI, Reinhardt RA (1993). Development and characterization of tetracycline-poly(lactide/glycolide) films for the treatment of periodontitis. Journal of Controlled Release, 23: 137-146.

23. Ahuja A, Ali J, Rahman S (2006) Biodegradable periodontal intrapocket device containing metronidazole and amoxycillin: formulation and characterisation. Die Pharmazie 61: 25-29.

24. Higashi K, Matsushita M, Morisaki K, Hayashi S, Mayumi T (1991) Local drug delivery systems for the treatment of periodontal disease. Journal of pharmacobiodynamics 14: 72-81

25. Kyun KD, Yun KS, Young JS, Pyoung CC, Heui SS (1990) Development of minocycline containing polycaprolactone film as a local drug delivery. Taehan Ch'ikkwa Uisa Hyophoe chi 28: 279-290.

26. Akıncıbay H, Şenel S, Yetkin Ay Z (2007) Application of chitosan gel in the treatment of chronic periodontitis. Journal of Biomedical Materials Research Part B: Applied Biomaterials 80: 290-296.

27. Jones DS, Woolfson AD, Djokic J, Coulter WA (1996) Development and mechanical characterization of bioadhesive semi-solid, polymeric systems containing tetracycline for the treatment of periodontal diseases. Pharmaceutical research 13: 1734-1738.

28. Bruschi ML, Jones DS, Panzeri H, Gremião MPD, de Freitas O, Lara EHG (2007) Semisolid Systems Containing Propolis for the Treatment of Periodontal Disease: In Vitro Release Kinetics, Syringeability, Rheological, Textural, and Mucoadhesive Properties. Journal of Pharmaceutical Sciences 96: 2074-2089.

29. Poison AM, Stoller NH, Hanes PJ, Bandt CL, Garrett S, Southard G (1996). 2 multicenter trials assessing the clinical efficacy of $5 \%$ sanguinarine in a biodegradable drug delivery system. Journal of Clinical Periodontology 23: 782-788.

30. Polson AM, Garrett S, Stoller NH, Bandt CL, Hanes PJ, Killoy WJ, Friesen LR (1997) Multi-Center Comparative Evaluation of Subgingivally Delivered Sanguinarine and Doxycycline in the Treatment of Periodontitis. II. Clinical Results. Journal of Periodontology 68: 119-126.

31. Noyan U, Yilmaz S, Kuru B, Kadir T, Acar O, Büget E (1997) A clinical and microbiological evaluation of systemic and local metronidazole delivery in adult periodontitis patients. Journal of clinical periodontology 24: 158-165.

32. Maze GI, Reinhardt RA, Payne JB, Maze C, Baker RA, Bouwsma OJ, Gerlach RW (1996) Gingival fluid tetracycline release from bioerodible gels. Journal of Clinical Periodontology, 23: 1133-1136.

33. Addy M, Langeroudi M (1984) Comparison of the immediate effects on the subgingival microflora of acrylic strips containing $40 \%$ chlorhexidine, metronidazole or tetracycline. Journal of Clinical Periodontology 11: 379-386.

34. Addy M, Hassan H, Moran J, Wade W, Newcombe R (1988) Use of Antimicrobial Containing Acrylic Strips in the Treatment of Chronic Periodontal Disease. Journal of Periodontology 59: 557-564. 
35. Noguchi T, Izumizawa K, Fukuda M, Kitamura S, Suzuki Y, Ikura H (1984) New method for local drug delivery using resorbable base material in periodontal therapy. The Bulletin of Tokyo Medical and Dental University 31: 145-153.

36. Taner IL, Özcan G, Doganay T, Iscanolu M, Taplamacioglu B, Gültekin SE, Balos K (1994) Comparison of the Antibacterial Effects on Subgingival Microflora of Two Different Resorbable Base Materials Containing Doxycycline. The Journal of Nihon University School of Dentistry 36: 183-190.

37. Higashi K, Morisaki K, Hayashi S, Kitamura M, Fujimoto N, Kimura S, Okada H (1990) Local ofloxacin delivery using a controlled-release insert (PT-01) in the human periodontal pocket. Journal of periodontal research 25: 1-5.

38. Kimura S, Toda H, Shimabukuro Y, Kitamura M, Fujimoto N, Miki Y, Okada H (1991) Topical chemotherapy in human periodontitis using a new controlled-release insert containing ofloxacin. I. Microbiological observation. Journal of Periodontal Research 26: 33-41.

39. Deasy PB, Collins AE, MacCarthy DJ, Russell RJ (1989) Use of strips containing tetracycline hydrochloride or metronidazole for the treatment of advanced periodontal disease. The Journal of pharmacy and pharmacology 41: 694-699.

40. Maze GI, Reinhardt RA, Agarwal RK, Dyer JK, Robinson DH, DuBois LM, Maze CR (1995). Response to intracrevicular controlled delivery of $25 \%$ tetracycline from poly(lactide/glycolide) film strips in SPT patients. Journal of clinical periodontology 22: 860-867.

41. Paolantonio M, D'Ercole S, Pilloni A, D'Archivio D, Lisanti L, Graziani F, Perinetti G (2009) Clinical, Microbiologic, and Biochemical Effects of Subgingival Administration of a Xanthan-Based Chlorhexidine Gel in the Treatment of Periodontitis: A Randomized Multicenter Trial. Journal of Periodontology 80: 1479-1492.
42. Friedman M, Golomb G (1982) New sustained release dosage form of chlorhexidine for dental use. I. Development and kinetics of release. Journal of periodontal research 17: 323-328.

43. Jones MN, Kaszuba M (1994) Polyhydroxy-mediated interactions between liposomes and bacterial biofilms. Biochimica et Biophysica Acta (BBA) Biomembranes 1193: 48-54.

44. Jones MN, Song YH, Kaszuba M, Reboiras MD (1997) The Interaction of Phospholipid Liposomes with Bacteria and Their Use in the Delivery of Bactericides. Journal of Drug Targeting 5: 25-34.

45. Esposito E, Cortesi R, Cervellati F, Menegatti E, Nastruzzi C (1997) Biodegradable microparticles for sustained delivery of tetracycline to the periodontal pocket: formulatory and drug release studies. Journal of Microencapsulation 14: 175-187.

46. Piñón-Segundo E, Ganem-Quintanar A, Alonso-Pérez V, Quintanar-Guerrero D (2005) Preparation and characterization of triclosan nanoparticles for periodontal treatment. International Journal of Pharmaceutics 294: 217-232.

47. Dung TH, Lee SR, Han SD, Kim SJ, Ju YM, Kim MS, Yoo H (2007) ChitosanTPP nanoparticle as a release system of antisense oligonucleotide in the oral environment. Journal of nanoscience and nanotechnology 7: 3695-3699.

48. Kaplish V, Walia MK, Kumar SLH (2013) Local Drug Delivery Systems in the Treatment of Peridontitis: A Review. Pharmacophore 4: 39-49.

49. Ahmad F, Iqbal Z, Jain N, Jain G, Talegaonkar S, Ahuja A, Khar R (2008) Dental Therapeutic Systems. Recent Patents on Drug Delivery \& Formulation 2: 58-67.

\section{Citation:}

Ismail NR, Rajabalaya R, David SR, Dhaliwal JS (2019) Current Status of Local Drug Delivery Systems in the Treatment of Periodontal Diseases. J Dent Maxillofacial Res Volume 2(3): 1-5. 